\title{
Seroprevalence of anti-streptolysin 0 antibodies and its clinical correlates in patients presenting at a tertiary care hospital of southern Haryana: A five year retrospective study
}

\author{
Chanchal Yadav', Jyoti Sangwan², Pratibha Mane ${ }^{3}$, Kirti Lohan $^{4}$, Kumkum Yadav ${ }^{5}$, \\ Mukesh Kumar6
}

\begin{abstract}
${ }_{1,5}$ Post Graduate Student, ${ }^{2}$ Professor, ${ }^{3}$ Professor and Head, ${ }^{4}$ Demonstrator, Department of Microbiology, Shaheed Hassan Khan Mewati Government Medical College, Nuh, Haryana, ${ }^{6}$ Professor, Department of Microbiology, Narayan Medical College and Hospital, Jamuhar, Bihar, India
\end{abstract}

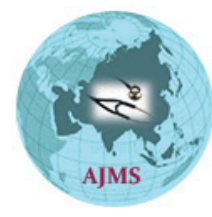

\section{A B S T R A C T}

Background: Streptococcus pyogenes, or group A Streptococcus, in addition to sore throat is responsible for certain non-suppurative diseases, such as acute rheumatic fever and post-streptococcal glomerulonephritis, which occur weeks after the acute infectious process. Anti-streptolysin-O (ASO) titer determination is one of important test sought by clinician. ASO has been shown to vary with age, geographical location, season, and site of infection. Aims and Objectives: To determine the seroprevalence of ASO antibodies and its clinical correlates in a tertiary healthcare facility of Southern Haryana. Materials and Methods: A retrospective cross-sectional study was done on 453 samples received in the Department of Microbiology, Shaheed Hassan Khan Mewati Government Medical College, Nuh, Haryana, on the blood samples received for the detection of ASO, over a period of 5 years (November 2015-October 2020). The data was analyzed for seroprevalence pattern of ASO and association of the same with clinical symptoms. Results: The seroprevalence of ASO antibodies in the present study was found to be $11.3 \%$. Females were more positive than males being $60.8 \%$ and $39.2 \%$, respectively. The most common age group involved was 11-20 years. Conclusion: The seroprevalence of ASO antibodies in the present study was found to be $11.3 \%$. Females showed more positivity compared to males. ASO positivity was seen more in the 11-20 years of the age group which could be due to the development of more competent immune system by this age. Arthralgia, fever, carditis, and sore throat were the common clinical presentations. The ASO test is an important investigation being easy to perform even in rural settings providing crucial clue for the diagnosis of post-streptococcal sequelae.

Key words: Arthralgia; Fever; Pharyngitis; Serology; Streptococcus pyogenes; Streptolysin O

\section{Access this article online}

Website:

http://nepjol.info/index.php/AJMS DOI: $10.3126 / a j m s . v 13 i 3.40885$

E-ISSN: 2091-0576

P-ISSN: 2467-9100

Copyright (c) 2022 Asian Journal of Medical Sciences

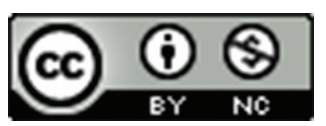

This work is licensed under a Creative Commons Attribution-NonCommercial 4.0 International License.

\section{INTRODUCTION}

Streptococcus pyogenes or group A Streptococcus (GAS), is an omnipresent and one of the most common human pathogens. It can cause a number of acute, common pyogenic infections, most frequent of which are pharyngitis and skin infections (impetigo). The two main non-suppurative sequelae associated with $S$. pyogenes are acute rheumatic fever (ARF) and post-streptococcal glomerulonephritis. The onset of these sequelae is mostly weeks after the acute infections process, mostly when the signs and symptoms have resolved. The pathogenesis of these complications is thought to be due to autoimmune response, wherein there is sharing of antigen between GAS and the host. ${ }^{1,2}$ 
The acute pyogenic infections are best diagnosed by isolation of the organism in culture. The non-suppurative diseases often occur at time when the organism may no longer be present, thus the serologic diagnosis is usually performed. Further, the serological diagnosis of infection might be necessary after the antimicrobial therapy has been started. ${ }^{3}$

For diagnosing the non-suppurative complications, evidence of recent preceding streptococcal infection is required, which can be done by serological evaluations. The serological tests include Anti-streptolysin O (ASO), anti-deoxyribonuclease $\mathrm{B}$, anti-hyaluronidase, and antistreptokinase antibodies. Post-streptococcal diseases include involvement of the heart and joint (RHD, RF), kidney (acute renal failure), abnormal involuntary movements, and other complications. The ASO antibody is directed toward the extracellular antigen of GAS. ASO along with a diagnosis of streptococcal infections or complications also aids in the follow-up and evaluating the effectiveness of treatments. ${ }^{3,4}$

ASO titer can vary with geographical location, season, age, and site of infection. However, it is not always practicable to obtain a second sample for titer determination, especially in developing countries. Hence, when a single specimen is available it requires a comparison with predetermined baseline value or upper limit of normal in a particular geographical area. ${ }^{5}$ Therefore, the present study was planned to determine the seroprevalence of ASO antibodies in patients presenting at a tertiary care health facility of Southern Haryana.

\section{Aims and objectives}

To determine the seroprevalence of ASO antibodies and its clinical correlates in a tertiary healthcare facility of Southern Haryana.

\section{MATERIALS AND METHODS}

A retrospective study was done in the serology section of Department of Microbiology, Shaheed Hassan Khan Mewati Government Medical College, Nuh, Haryana, on the blood samples received for the detection of ASO, over a period of 5 years (November 2015-October 2020). Institutional Ethics Committee approval was obtained wide letter No SHKM/IEC/2021/16 dated 04/03/2021. Serum separation was done by centrifuging the samples at $1500 \mathrm{rpm}$ for $10 \mathrm{~min}$. The test was done using rapid test kit (Aspen laboratories), based on latex slide agglutination.

This method is based on an immunological reaction between streptococcal antibodies in the test sample and exo-enzymes bound to biologically inert latex particles. Positive and negative controls, provided along with the kits were put with every run of the test process. A positive test is indicated when agglutination is seen within $2 \mathrm{~min}$ of adding the latex reagent in the sera sample and a test is considered negative when there is no agglutination seen. The sensitivity of the latex reagent had been adjusted to give agglutination when the level of ASO is greater than $200 \mathrm{IU} / \mathrm{mL}$ as per kit. These cut off are determined using epidemiological and clinical studies. The results obtained for ASO detection along with other information available during 5 years, from November 2015 to October 2020 were analyzed.

\section{Statistical analysis}

Qualitative data and quantitative data were expressed in the form of mean \pm standard deviation and significance of difference was assessed by chi-square test. A $\mathrm{P}<0.05$ was decided as statistically significant. All statistical calculations were done using Microsoft Excel Version 7 (Microsoft Corporation, NY, USA) and SPSS Version 20.0.

\section{RESULTS}

Serum samples of 453 patients were tested for ASO antibody over a period of 5 years. The ASO antibody titers $>200 \mathrm{IU} / \mathrm{mL}$ were found in $51(11.3 \%)$ patients. Of these 51 patients, the prevalence was higher in females $31(60.8 \%)$ as compared to males $20(39.2 \%)$ as shown in Figure 1. Age distribution of ASO antibody-positive samples reveals the highest prevalence of $23.8 \%$ among samples from 11 to 20 year age group followed by $8.6 \%$ in $1-10$ years of age group as shown in Table 1. Specialty-wise distribution is depicted in Figure 2. 281 samples were received from the Pediatrics department out of which $36(12 \%)$ were positive for ASO antibody. 107 samples were received from the

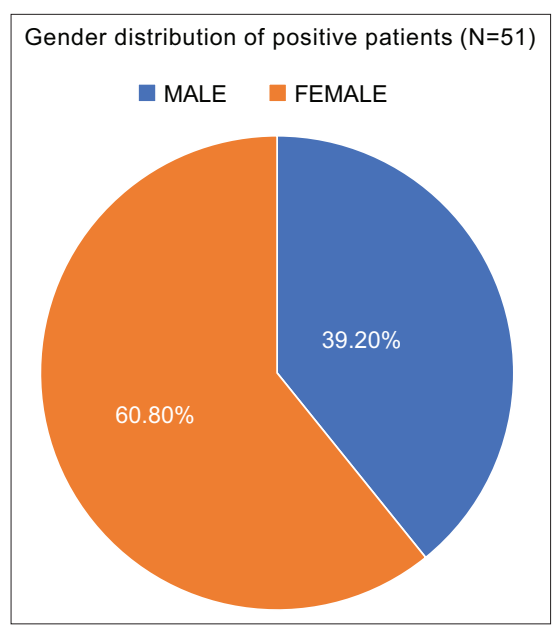

Figure 1: Gender distribution of ASO positive patients. ASO: Antistreptolysin-O 
Medicine department out of which $6(5.6 \%)$ were positive, a total of 64 samples were received from Orthopaedics out of which $9(14 \%)$ were positive for ASO. The single sample received from Dermatology was negative for ASO. As depicted in Table 2; sore throat, arthralgia, and carditis were the most common reasons behind requisition of ASO testing. ASO seropositivity was seen more associated with fever, glomerulonephritis, arthralgia followed by sore throat and carditis and least with Impetigo $(\mathrm{P} \leq 0.05)$ (Table 2).

\section{DISCUSSION}

In infections caused by beta-hemolytic streptococci, streptolysin $\mathrm{O}$ is one of the two hemolytic exotoxins released by the bacteria. This stimulates the production of ASO antibodies in the human body. ${ }^{1-3}$ The throat cultures however crucial, can be falsely negative due to previous antibiotic treatment, masked by growth of commensals and non-suppurative presentations. Similarly, throat cultures can be false positive due to a carriage state, thereby considered less useful for diagnosis. Hence streptococcal antibody tests have become a method commonly used to provide evidence of preceding streptococcal infection. ${ }^{4,5}$

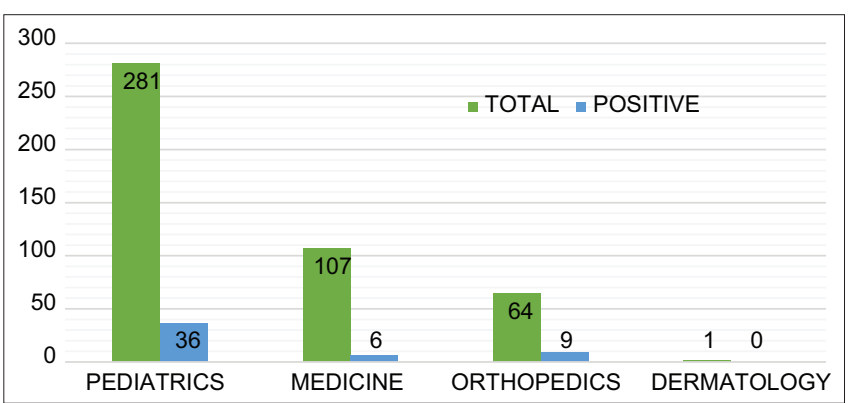

Figure 2: Specialty wise distribution of ASO positivity. ASO: Antistreptolysin-O

\section{Table 1: Age wise distribution of patients}

\begin{tabular}{lccc}
\hline $\begin{array}{l}\text { Age group } \\
\text { (years) }\end{array}$ & $\begin{array}{c}\text { Number of } \\
\text { patients }\end{array}$ & $\begin{array}{c}\text { Positive } \\
\text { (Titre>200 } \mathbf{~ I U / m L )}\end{array}$ & Percentage \\
\hline $0-10$ & 174 & 15 & 8.6 \\
$11-20$ & 126 & 30 & 23.8 \\
$21-30$ & 94 & 6 & 6.3 \\
$31-40$ & 40 & 0 & 0 \\
$>40$ & 19 & 0 & 0 \\
Total & 453 & 51 & 11.3 \\
\hline
\end{tabular}

The ASO antibody estimation is the most common, best standardized, simple, cost-effective, and practical test for detecting antecedent streptococcal infection. Even a single ASO titer is a useful investigating tool supporting the confirmation of acute rheumatic fever diagnosis. In acute phase, the ASO titer is elevated and as the disease progress a subsequent lower titer level is seen. ${ }^{3}$

The seroprevalence of ASO in the present study was found out to be $11.3 \%$. This was lower than the prevalence reported from Rohtak, Hyderabad, and Bhadrak being $20.4 \%, 27 \%$, and $29.26 \%$, respectively. ${ }^{6-8}$ Lower prevalence rate was reported by Hatkar et al., in Maharashtra, being $6.03 \%$. 'The highest prevalence was reported by Khan et al., 2012, Banke Nepal wherein they reported ASO prevalence of $45.45 \%{ }^{10}$

Of the total ASO-positive cases, $39.2 \%$ were male and $60.8 \%$ were female. The seroprevalence rate was higher in females as compared to male of the region. Similar findings were reported by other studies. ${ }^{6-8,10}$ This could be explained by the fact that autoimmune phenomena are more seen in female compared to male. However, Hatkar et al., 2017 in their tertiary hospital-based study at Maharashtra found higher seropositivity in male as compared to female.?

In our study, the highest ASO positivity was seen in 11-20 years age group patients followed by $1-10$ years and 21-30 years, with no positivity detected in more than 30 years of age. Similar findings were reported from other studies. ${ }^{6,7,9,10}$ The obvious reason for this is that the most common age group for non-suppurative streptococcal sequelae such as rheumatic fever and post-streptococcal glomerulonephritis is $5-15$ years, first occurrence being rare in adults. ${ }^{11}$ However, Kumar 2014, from Bhadrak India, found the majority of seropositive cases belonging to the age group 21-30 years. ${ }^{8}$

While studying the presenting features leading to requisition of ASO test, it was found that sore throat, arthralgia, and carditis were investigated more for ASO compared to fever and glomerulonephritis. Contrary to the present study, Mandal et al., reported more investigation of carditis patient compared to sore throat and arthralgia. ${ }^{12}$

\section{Table 2: Presenting symptoms that led to ASO requisition and ASO positivity in relation to them}

\begin{tabular}{|c|c|c|c|c|c|c|c|c|c|c|c|c|}
\hline \multirow{2}{*}{$\begin{array}{l}\text { Type of symptoms } \\
\text { Number of patients (N) }\end{array}$} & \multicolumn{2}{|c|}{ Carditis } & \multicolumn{2}{|c|}{ Arthralgia } & \multicolumn{2}{|c|}{$\begin{array}{l}\text { Tonsillitis/ } \\
\text { sore throat }\end{array}$} & \multicolumn{2}{|c|}{ Glomerulonephritis } & \multicolumn{2}{|c|}{ Impetigo } & \multicolumn{2}{|c|}{ Fever } \\
\hline & Total & $+\mathrm{ve}$ & Total & +ve & Total & $+v e$ & Total & $+v e$ & Total & $+v e$ & Total & $+v e$ \\
\hline & 56 & 5 & 160 & 24 & 216 & 20 & 10 & 1 & 1 & 0 & 10 & 1 \\
\hline Proportion of positive patients & \multicolumn{2}{|c|}{0.089} & \multicolumn{2}{|c|}{0.15} & \multicolumn{2}{|c|}{0.092} & \multicolumn{2}{|c|}{0.1} & \multicolumn{2}{|c|}{0} & \multicolumn{2}{|c|}{0.1} \\
\hline$P$ value & \multicolumn{2}{|c|}{$<0.00001^{*}$} & \multicolumn{2}{|c|}{$<0.00001^{*}$} & \multicolumn{2}{|c|}{$<0.00001^{*}$} & \multicolumn{2}{|c|}{$0.0114^{*}$} & \multicolumn{2}{|c|}{0.3} & \multicolumn{2}{|c|}{$0.0114^{*}$} \\
\hline
\end{tabular}


While studying the association of symptoms with ASO positivity, it was observed that arthralgia was associated with $15 \%$ positivity compared to fever $(10 \%)$, glomerulonephritis $(10 \%)$, sore throat $(9.2 \%)$, and carditis $(8.9 \%)$. The difference being significant $(\mathrm{P} \leq 0.05)$. The same has been stated by Walker et al. ${ }^{11}$ However, Mandal et al., found more positivity in carditis patients and sore throat patients. ${ }^{12}$ Possible explanations could be due to geographical variation or lesser positivity and small sample size of our study. Also in spite of $10 \%$ positivity in fever cases, such symptom was investigated less for ASO.

To conclude, the ASO antibodies are a simple, costeffective way for detecting recent streptococcal infection. It becomes all the more important corroborating test while considering the diagnosis of non-suppurative sequelae of GAS infection. Although ASO titer has provided a useful guideline to physicians, it has been shown to vary with age, geographical location and site of infection.

\section{Limitations of the study}

The study being retrospective, co-relation with the clinical outcome and follow-up could not be done.

\section{CONCLUSION}

The seroprevalence of ASO antibodies in our study was found to be $11.3 \%$. Females showed more positivity compared to males. ASO positivity was seen more in the 11-20 years of age group which could be due to the development of more competent immune system by this age. The ASO test is cheaper and easy to perform test even in rural settings providing crucial evidence for post-streptococcal sequelae. ASO becomes even helpful when culture is negative and patient already has taken antibiotics.

\section{ACKNOWLEDGMENT}

None.

\section{REFERENCES}

1. Kotby AA, Habeeb NM and Ezz El Elarab S. Antistreptolysin O titer in health and disease: Levels and significance. Pediatr Rep. 2012;4(1):25-29.

https://doi.org/10.4081/pr.2012.e8

2. Zafindraibe NJ, Randriamanantany ZA, Rajaonatahina DH, Andriamahenina $\mathrm{R}$ and Rasamindrakotroka $\mathrm{A}$. Current practice about the evaluation of antibody to streptolysin O (ASO) levels by physicians working in Antananarivo, Madagascar. Afr Health Sci. 2014;14(2):384-389.

https://doi.org/10.4314/ahs.v14i2.14

3. Sen ES and Ramanan AV. How to use antistreptolysin O titre. Arch Dis Child Educ Pract Ed. 2014;99(6):231-237.

https://doi.org/10.1136/archdischild-2013-304884

4. Ben-Chetrit E, Moses AE, Agmon-Levin N, Block C and Ben-Chetrit E. Serum levels of anti-streptolysin $O$ antibodies: Their role in evaluating rheumatic diseases. Int $\mathrm{J}$ Rheum Dis. 2012;15(1):78-85.

https://doi.org/10.1111/j.1756-185X.2011.01668.x

5. Ismail EH. Rheumatic fever. Baillieres Clin Rheumatol. 2006;9:111-120.

6. Chillana S, Baka $K$ and Girwan A. Seroprevalence of antistreptolysin $\mathrm{O}$ antibody in a tertiary health care centre in north India. Int J Curr Res. 2018;10(9):73568-73570. https://doi.org/10.24941/ijcr.32247.09.2018

7. Sheerin $N$, Nasaruddin $M$, Fatima $Y$ and Shailaja $V$. Seroepidemiological study of antistreptolysin o antibodies in a tertiary care Centre in South India. Glob J Res Anal. 2018;7(11):2277-8160.

https://doi.org/10.36106/gjra

8. Kumar K. Prevalence of antistreptolysin $\mathrm{O}$ antibodies at Bhadrak region, India. Hippocratic J Unani Med. 2014;9:91-97.

9. Hatkar $S$, Kotgire $S$ and Siddhiqui $S$. Sero-prevalence of antistreptolysin ' $\mathrm{O}$ ' antibodies at tertiary care hospital: A two year of prospective study. Int J Med Microbiol Trop Dis. 2017;3(1):24-26. https://doi.org/10.18231/2455-6807.2017.0006

10. Khan S, Singh P, and Siddiqui AH. Prevalence of anti-streptolysin o antibodies at banke region Nepal. Bali Med J. 2012;1(3):98-100. https://doi.org/10.15562/bmj.v1i3.22

11. Walker MJ, Barnett TC, McArthur JD, Cole JN, Gillen CM, Henningham $A$, et al. Disease manifestations and pathogenic mechanisms of Group A Streptococcus. Clin Microbiol Rev. 2014;27:264-301. https://doi.org/10.1128/CMR.00101-13

12. Mandal A, Saha P, Mondal T and Kundu P. Evaluation of ASO test and correlation with clinical request in a tertiary care teaching hospital: An insight study. IOSR J Dent Med Sci. 2018;17(9):55-58. https://doi.org/10.9790/0853-1709025558

\footnotetext{
Authors' Contributions:

CY- Concept and design of the study, prepared first draft of manuscript; JS- Interpreted the results; reviewed the literature and manuscript preparation; JS, PM, KL, KY, MK- Coordination, statistical analysis and interpretation and revision of the manuscript

Work attributed to:

Shaheed Hassan Khan Mewati Government Medical College, Nuh - 122 107, Haryana, India

Orcid ID:

Chanchal Yadav - (1) https://orcid.org/0000-0001-6806-069X

Dr. Jyoti Sangwan - $\mathrm{https://orcid.org/0000-0001-8410-2212}$

Pratibha Mane - 1 https://orcid.org/0000-0001-7518-0155

Kirti Lohan - (1) https://orcid.org/0000-0001-6799-5688

Kumkum Yadav - 1 https://orcid.org/0000-0003-4815-9646

Mukesh Kumar - https://orcid.org/0000-0003-4017-4008

Source of Funding: None, Conflicts of Interest: None.
} 